\title{
A DOCÊNCIA NA EDUCAÇÃO A DISTÂNCIA NO ENSINO SUPERIOR: REFLEXÕES NA PERSPECTIVA DOS PROFESSORES
}

\author{
CRICIUMA/SC JULHO/2018
}

\author{
ELISA NETTO ZANETTE - UNESC - enz@unesc.net \\ KAMILA VIEIRA ALVES - UNESC - kamilavieiraalves@gmail.com \\ MICHELE DOMINGOS SCHNEIDER - UNESC - michele.schneider@unesc.net
}

Tipo: Investigação Científica (IC)

Natureza: Relatório Final de Pesquisa

Categoria: Pesquisa e Avaliação

Setor Educacional: EDUCAÇÃO SUPERIOR

\begin{abstract}
RESUMO
Relata-se no artigo, o trabalho investigativo que objetivou analisar o processo de docência na Educação a Distância (EaD), no Curso Superior de Tecnologia em Gestão Comercial (TGC) da Universidade do Extremo Sul Catarinense (UNESC). Compreender as implicações e as distintas perspectivas relacionadas as novas responsabilidades nas ações pedagógicas dos docentes na EaD, foi desencadeador na motivação para a pesquisa. A pesquisa é bibliográfica, categorizada em estudo de caso. Os dados foram coletados a partir da aplicação de questionário aos docentes que atuaram no referido curso e contribuíram na formação da primeira e segunda turma de formados. Os procedimentos metodológicos contemplaram a revisão bibliográfica, a elaboração de instrumento de pesquisa, a aplicação do referido instrumento, a coleta e análise dos dados. Durante 0 desenvolvimento da pesquisa, foi consultado o Projeto Pedagógico do Curso (PPC) com o objetivo de contribuir na elaboração do instrumento de pesquisa e na análise dos dados. Fundamentou-se teoricamente a partir das produções científicas na área do estudo. Conclui-se que, as novas atribuições da docência na EaD, organizadas na atuação como professor de disciplina, autor de material didático e tutor, constituem-se em desafios no desempenho dos diferentes papéis nesta modalidade de ensino. Dentre eles, a autoria de material didático, o domínio dos diversos recursos de comunicação e interação, a adequação das aulas por meio de web-conferência, entre outros. Entretanto, avaliaram como positiva a experenciação da docência na EaD e a influência exercida na significativa mudança nas práticas pedagógicas na educação presencial.
\end{abstract}

Palavras-chave: Ensino Superior, Educação a Distância, Avaliação, Docência.

\section{AGRADECIMENTOS}

PROGRAMA INSTITUCIONAL DE BOLSAS DE INICIAÇÃO CIENTÍFICA (PIBIC) E, AO PROGRAMA INSTITUCIONAL DE GRUPOS DE PESQUISA DA UNIVERSIDADE DO EXTREMO SUL CATARINENSE (UNESC). 


\section{INTRODUÇÃO}

A Educação a Distância (EaD), se constitui numa modalidade de educação que se apresenta com diferentes modos de organização pedagógica. O desenvolvimento das Tecnologias de Informação e Comunicação (TICs) e dos Ambientes Virtuais de Aprendizagem (AVAs), recursos usuais das novas gerações, tem potencializado e promovido reflexões sobre a relevância da ressignificação das práxis docentes no contexto da educação presencial e a distância. Assim, evidencia-se a relevância na avaliação permanente dos processos de ensino e aprendizagem na EaD, pela efetivação diagnóstica de uma situação e acompanhamento, oportunizando condições para intervenções e reorganizações quando necessário. A docência nesta modalidade implica num novo perfil profissional, com o professor assumindo novas atribuições. Compreender as implicações e as distintas perspectivas relacionadas as ações pedagógicas dos docentes na $\mathrm{EaD}$, foi desencadeador na motivação para a pesquisa. $\mathrm{Na}$ Universidade do Extremo Sul Catarinense (UNESC), o Curso Superior de Tecnologia em Gestão Comercial (TGC) é ofertado na modalidade a distância desde 2013-2 e formou sua primeira turma em 2015-2. Neste contexto, definiu-se como problema da pesquisa: Como ocorre o processo de docência na EaD, no Curso Superior de TGC da UNESC, na perspectiva dos professores.

A pesquisa objetivou, analisar o processo de docência na EaD, no Curso Superior de Tecnologia em Gestão Comercial da UNESC na perspectiva dos professores. Parte-se do pressuposto que, conhecer a visão do docente no seu processo de experienciação da docência na EaD, as características, as possibilidades e desafios, poderá contribuir nas reflexões e melhorias nas práxis docente no curso e nos demais a serem ofertados pela Instituição de Ensino Superior (IES). A pesquisa se constitui em estudo de caso, é bibliográfica, com abordagem quantitativa e qualitativa de análise de dados. Os dados foram coletados a partir da aplicação de questionário aos docentes que atuaram no referido curso e contribuíram na formação da primeira e segunda turma de formados. Apresentam-se a seguir, os fundamentos teóricos que subsidiaram a coleta e a análise dos dados, o percurso metodológico adotado, a apresentação e a análise dos dados, com as conclusões preliminares e as referências.

\section{A EDUCAÇÃO A DISTÂNCIA NA SOCIEDADE CONTEMPORÂNEA}

A significativa expansão e reconhecimento da modalidade EaD ocorreu de forma acentuada nos últimos anos, em decorrência das novas formas de organização e comunicação na sociedade contemporânea, potencializada pelo desenvolvimento das TICs. Os modelos e projetos de viabilização da EaD variam quanto ao grau de 
presencialidade, nível de interatividade, tipos de recursos didáticos utilizados, nível atuação e escala de abrangência, como afirma Hack (2011). Os princípios educacionais, citados por Cortelazzo (2013), como autonomia, ação comunicativa, colaboração e cooperação, acessibilidade e equidade, devem nortear as concepções pedagógicas dos projetos em EaD, na compreensão dos marcos conceituais, na reflexão sobre os componentes epistemológicos, as abordagens e estratégias que viabilizam os projetos nessa modalidade (ZANETTE, et. al., 2012, p. 16). Para Bezerra e Carvalho (2011, p.237) se faz necessário que as ações educativas dos docentes, estejam centradas "na construção de um processo educativo alicerçado na interatividade e na criatividade, na qual deverá provocar discussões, duvidas e instigar a aprendizagem dos estudantes". Atualmente, vários recursos didáticos e tecnológicos são utilizados para potencializar a comunicação, o acesso à informação e a aprendizagem nesta modalidade de educação. Destacam-se os recursos associados aos Ambientes Virtuais de Aprendizagem (AVAs), das webconferências, teleconferências, videoaulas, entre outros. Segundo Oliveira (2013, p.115) "no ambiente virtual ferramentas com e-mail, chat, fórum, lista de atividades, vídeo aula possibilitam formas de interação síncrona e assíncrona entre professor e aluno", relevantes nesta modalidade com docentes e discentes separados fisicamente ou temporalmente.

Para a efetiva aprendizagem é necessário à interação e colaboração de ambas as partes, professor e alunos. A maioria dos cursos a distância do modelo apoiado em tutoria, caracteriza-se pela interação, segundo Cortelazzo (2013, p.138). "Os alunos interagem com o material didático, lendo texto e realizando as atividades solicitadas". As várias linguagens no mundo da educação, relacionadas a linguagem digital, são um dos meios mais fortes de comunicação principalmente na modalidade de EaD. Estas linguagens também se refletem nos materiais didáticos e se apresentam como linguagem sonora, audiovisual e escrita em forma de sistema integrado de materiais didáticos e recursos tecnológicos. Assim, a definição do material didático configura opções de linguagens e suportes tecnológicos. Envolve desde o conhecimento representado pelo conteúdo, o desenho desse material, veiculado em um determinado suporte, utilizando uma determinada linguagem.

\section{OS SABERES DA DOCÊNCIA NA EDUCAÇÃO A DISTÂNCIA: AS DIFERENTES IMPLICAÇÕES E PERSPECTIVAS}

Fatores diversos interferem diretamente no ensino e na aprendizagem na $\mathrm{EaD}$, como citam Bezerra e Carvalho (2011, p.237): a atuação do professor, a autonomia e motivação do aluno, o sistema de monitoria e tutoria, os recursos didáticos e tecnológicos de apoio, entre outros. Na atualidade, a efetivação dos processos processo 
de ensino e aprendizagem na EaD, vincula-se ao uso sistemático de meios tecnológicos de comunicação e interação. Com isso, há necessidade de estruturação de equipes multidisciplinares que apoiam o professor e são responsáveis por várias etapas de execução do processo de $\mathrm{EaD}$, desde a produção do material até o acompanhamento dos estudantes.

A importância do trabalho de equipes multidisciplinares na $\mathrm{EaD}$, contribuindo com uma parte do processo educacional de forma cooperativo e colaborativo também é citado por Chaquime e Mill (2012). Interferem na docência mas decorrem da especificidade nos modelos de EaD, da forma como as aulas ou o curso são planejados e ofertados. Bezerra e Carvalho (2011, p.234) afirmam que "as categorias e funções dos profissionais desta equipe multidisciplinar apresentam traços em comum nas diferentes instituições, embora a nomenclatura possa variar ocasionalmente". Constituem estas equipes, os profissionais técnicos administrativos, de gestão, os docentes (professorautor, de disciplina e tutor), os monitores, entre outros. Para Mill (2010), o conjunto articulado de profissionais, necessário para a realização das atividades pedagógicas na $\mathrm{EaD}$, constitui a polidocência. O professor, que na educação presencial, organiza usualmente sozinho suas ações pedagógicas, na EaD, o docente têm suas funções expandidas e divide atribuições com outros profissionais, que pode ocorrer na perspectiva de uma docência compartimentada ou uma docência compartilhada e colaborativa (MILL, 2010). Assim, a polidocência pode ser observada em perspectivas distintas traz consigo algumas implicações didático-pedagógicas e de gestão.

Evidencia-se assim na EaD a exigência de um perfil profissional diferenciado de docente considerando que as categorias profissionais são redefinidas para atuações como professor de disciplina (ou conteudista), professor autor, professem tutor (virtual e presencial), designer instrucional, entre outras. Portanto, sua atuação deve estar embasada na complexidade do fazer pedagógico, considerando a multiplicidade de saberes necessários para docência como citam Tardif (2008) e Schon (1995). Os saberes experienciais ou práticos, são desenvolvidos pelos próprios professores, no exercício de suas funções e na prática de sua profissão, segundo Shön (1995) e Tardif (2008). Neste sentido, a docência na EaD diferencia-se em relação a educação presencial, na questão do domínio dos recursos da TICs e na forma de atuação do professor que interage com alunos distantes fisicamente mas próximos virtualmente. Para Oliveira (2013, p. 100), "[...] o professor precisa, acima de tudo, aprender a aprender, aprender a ser e a conviver em um ambiente virtual".

O professor na EaD tem papel importante, na organização dos conteúdos, das atividades e principalmente em aproximação com os estudantes e tutores. Neste 
contexto o professor é o parceiro do estudante na construção do conhecimento e atuando em parceria com o tutor, ele deixa de ser um entidade individual. É requerido do professor o domínio de tecnologias e a capacidade de trabalhar em equipe e com pessoas em diversas áreas do conhecimento (SCHNEIDER; ARAUJO; BEHAR, 2013). O papel do professor na EaD é diferenciado, pois não lhe cabem improvisações, todo o trabalho e material utilizado precisam ser planejados antecipadamente. Em se tratando de uma entidade coletiva, o professor na EaD, precisa conhecer e reconhecer sua equipe de trabalho. No âmbito das atribuições pedagógicas, compete ao docente, definir os fundamentos teóricos do trabalho, selecionar e preparar o conteúdo, definir os objetivos, bibliografias, materiais de apoio, entre outros, segundo Schneider, Araujo e Behar (2013).

Dentre as categorias e funções dos profissionais na EaD, citados por Bezerra e Carvalho (2011) e Mill (2010) o professor tutor tem papel relevante no acompanhamento do dos alunos e na articulação com docentes autores, de disciplinas e demais integrantes da equipe multidisciplinar. Discussões se fazem, sobre a responsabilidade do tutor em ensinar, ou apenas mediar e apoiar o processo (SCHNEIDER; ARAUJO; BEHAR, 2013). Para Schmid (2004), o tutor tem como atribuição, desenvolver os aspectos comunicacionais, de interação e intelectual, no entanto não exerce a função de ensino, uma vez, que a produção e seleção de materiais é de responsabilidade do professor.

As ferramentas de comunicação auxiliam o papel do tutor, promovem uma comunicação mais rápida e eficaz, permitem a armazenagem das informações. A intervenção do tutor é diferenciada do professor presencial, pois apresenta dimensões de atuação únicas da modalidade a distância e tangem as dimensões de tempo, risco e oportunidade.O aspecto de risco está em relacionado ao não aproveitamento deste momento de contato com a aluno. O não aproveitamento pode ocasionar uma visão parcial e distorcida do aluno com relação ao conteúdo, disciplina ou curso (LITWIN, 2001). Em uma visão ampla, as atribuições do tutor permeiam as funções básicas de facilitar a aprendizagem por meio das tecnologias, apoiar o progresso do estudante, promover o apoio afetivo e envolver-se na avaliação da aprendizagem (MATTAR, 2012).

\section{PERCURSO METODOLÓGICO}

A pesquisa desenvolvida é bibliográfica e constitui-se como um estudo de caso. Contempla as abordagens qualitativas e quantitativas de coleta e análise de dados. Fundamentou-se teoricamente nas publicações científicas da área. A população alvo da pesquisa foi composta pelos docentes do curso superior a distância, de TGC da 
UNESC. A amostra foi constituída pelos docentes que aceitaram participar de forma voluntária da pesquisa. Os dados tabulados e analisados forma obtidos a partir dos instrumentos utilizados: diário de bordo, questionário e Projeto Pedagógico do Curso (PPC).

\section{RESULTADOS E DISCUSSÃO: AVALIAÇÃO DO PROCESSO DE DOCÊNCIA NA PERCEPÇÃO DOS PROFESSORES}

Avaliar permanentemente a modalidade de $\mathrm{EaD}$ é fundamental para ampliar os debates e reflexões visando a melhoria do processo pedagógico. Na consulta ao PPC de TGC da UNESC, verificou-se que, são oferecidas anualmente 120 vagas e iniciou em 2013-2. Na arquitetura pedagógica do curso, conta a incorporação dos recursos das TICs, especialmente com uso de redes e de sistemas multimídia, que é justificado pelos ganhos em escala no atendimento e na qualidade da interação entre alunos e professores (UNESC/PPC, 2015). A polidocência é exercida por Professor de Disciplina, Conteudista e Tutor. São apoiados por equipe multidisciplinar nas atividades da docência com formação continuada para a docência na EaD.

$\mathrm{Na}$ pesquisa desenvolvida, participaram 70,8\% (17) dos 24 docentes do curso que atuaram como professores e/ou tutores desde 2013-2. Foram estabelecidos três blocos de análise: auto avaliação docente, avalição do material didático e recursos didáticos e, desempenho discente. Nas questões fechadas, a escala de avaliação situou-se entre 5 e 1: 5 (muito satisfeito); (4) satisfeito; (3) parcialmente satisfeito; (2) insatisfeito; (1) muito insatisfeito; (0) não se aplica (desconheço). Dos docentes participantes da amostra, $58,8 \%$ são do sexo masculino, 58,8\% tem idade entre 36 e 55 anos, 58,8\% atua no ensino superior a mais de 11 anos. Em sua maioria (70,6\%) são mestres com formação na área. A maioria dos docentes tem dedicação exclusiva a educação superior $(88,35 \%)$. O sistema de contrato de trabalho na instituição situa-se em horista, tempo parcial e tempo integral. Dos docentes pesquisados, $07(41,2 \%)$ são professores horistas, $02(11,8 \%)$ são contratados como tempo parcial e $08(47,1 \%)$ são docentes em tempo integral. O curso de TGC representa o primeiro curso superior da instituição na modalidade a distância. Neste sentido, observou-se que, os docentes em sua maioria, desenvolveram três atribuições distintas no curso: Professor de disciplina (100\%), tutor na sua disciplina $(70,6 \%)$ e $03(17,6 \%)$ docentes atuaram como tutores de outras disciplinas do curso. 08 (47,1\%) dos docentes foram autores individuais do livro didático, $05(29,4 \%)$ são autores coletivos com a participação de outros docentes na produção do referido livro.

Apresenta-se a seguir parte dos dados da análise dos três indicadores já citados, 
obtidos no desenvolvimento da pesquisa. Optou-se pelo somatório das escalas de satisfação 5 (muito satisfeito) e 4 (satisfeito), indicada no trabalho como satisfeito para a apresentação dos resultados. Assim, 81,3\% escolheram estes indicadores na avaliação do seu planejamento. $81,3 \%$ afirmaram que o PPC possibilitou orientar as suas estratégias pedagógicas propostas na disciplina. 93,8\% consideram-se satisfeitos com seu desempenho docente no ambiente virtual - AVA e web conferência. No mesmo indicador, situaram-se $93,8 \%$ dos docentes, sobre considerar que conseguiu gerar os temas-conceitos necessários para a aprendizagem dos seus discentes no desenvolvimento da(s) sua(s) disciplina(s). 100\% afirmaram estar satisfeitos com o seu domínio de conhecimento em relação a sua disciplina. Como afirmam Tardif (2008) e Shön (1995) os saberes experienciais, relevantes na atuação docente, são inerentes à prática pedagógica, desenvolvidos na atuação e formação do professor, embasados nas mais diversas atividades e incorporados sob a forma de conhecimento, habilidades e competências.

O apoio da equipe multidisciplinar no desenvolvimento da disciplina foi considerado importante para 93,8\% dos docentes. Como cita Mill (2010) a polidocência se caracteriza na EaD por necessitar de um conjunto articulado de profissionais, necessário para a realização das atividades pedagógicas. A formação docente é fundamental na educação presencial e a distância. 56,3\% afirmam estar satisfeitos com a sua formação docente para atuar na EaD e 87,5\% participaram de todas as formações promovidas pela UNESC. $50 \%$ afirmaram que a formação ocorreu efetivamente, durante a atuação na docência com a orientação da assessoria pedagógica da UNESC.

$\mathrm{Na}$ autoavaliação da tutoria, 100\% afirmaram estar satisfeitos com as orientações recebidas do professor da disciplina. Como cita Cortelazzo (2013), a interação e a colaboração devem atender aos diferentes níveis de ações desenvolvidas entre os participantes. Todos afirmaram ter domínio de conteúdo na disciplina de atuação. Todos estão satisfeitos com o desempenho no ambiente virtual como tutor. 83,3\% afirmam estar satisfeitos com o atendimento ao discente de forma a contribuir com a sua permanência no curso, auxiliando na organização do tempo, no cumprimento dos cronogramas, nas sugestões, entre outras. As atribuições do tutor, segundo Mattar (2012), permeiam as funções básicas de facilitar a aprendizagem por meio das tecnologias, apoiar o progresso do estudante, promover o apoio afetivo e envolver-se efetivamente na avaliação da aprendizagem. Na avalição dos recursos didáticos, 94,1\% responderam estar satisfeitos com a qualidade do livro didático e $82,3 \%$ avaliaram da mesma forma a qualidade das vídeo-aulas. É relevante citar que a maioria dos docentes são autores do material didático. 
Os resultados sobre a qualidade das estratégias e metodologias didáticas utilizadas nas aulas mostram um bom nível de satisfação dos docentes que registraram estar muito satisfeitos e satisfeitos. Da mesma forma, a qualidade das ferramentas do AVA utilizadas nas aulas para contato entre alunos e com professor, mostrou um elevado nível de satisfação. Questionados sobre os principais desafios enfrentados pelo docente EaD, o professor $A$, citou: "adaptação a nova metodologia, domínio do moodle, adequação das aulas para conferência via web, elaboração do material didático e das atividades de aprendizagem". Para o professor B, o maior desafio se situa na "interação com aluno e elaboração de atividades que levassem o aluno a aprendizagem". Outras questões foram apontadas, como: gravar vídeo-aulas, desvincular do experiência do ensino presencial; manter os alunos motivados; produzir material didático, interagir com o estudante durante a aula síncrona, entre outras. Como sugestão para a coordenação do curso, indicaram, basicamente a formação em metodologias ativas, a continuidade das capacitações e acompanhamento das atividades pedagógicas de EAD, a melhoria das TICs nas aulas síncronas. Para os tutores, é relevante ampliar o tempo para as correções e respostas aos acadêmicos; melhorar os espaços físicos de atendimento; ampliar o espaço de formação para o uso do AVA; buscar formas de ampliar a participação dos acadêmicos e estabelecer um canal contínuo de diálogo.Os tutores avaliaram a participação dos alunos na tutoria como de baixa frequência, em sua maioria. Neste contexto, conclui-se que, a análise da docência a partir avaliação dos docentes, teve um índice geral bem avaliado nas três categorias da amostra, o que valida à proposta pedagógica do curso, a formação e a atuação dos mesmos.

\section{CONCLUSÃO}

A EaD na contemporaneidade está associada ao uso sistemático de tecnologias digitais, com foco na comunicação e interação, como se verificou na pesquisa. A constituição de equipes multidisciplinares integram os projetos nesta modalidade de educação. São responsáveis pelas diversas etapas de execução do projeto pedagógico dos cursos diversos. A docência na $\mathrm{EaD}$, nas diferentes funções de autoria, gestão de disciplinas e tutoria, se constitui em desafios constantes. São atribuídas ao professor no exercício de suas atividades, os saberes docentes e o domínio dos recursos tecnológicos utilizados ação pedagógica. A construção de um processo educativo é apoiada no modelo da colaboração, interatividade e na criatividade, de forma a promover discussões, questionamentos e reflexões que potencializem a aprendizagem dos estudantes. Nos resultados da pesquisa desenvolvida com os docentes do curso, verificou-se um índice elevado de satisfação dos mesmos com os indicadores analisados. Os resultados da pesquisa apontam elementos importantes para a continuidade da proposta pedagógica do curso. Conclui-se que, as novas atribuições da docência na EaD, organizadas na 
atuação como professor de disciplina, autor de material didático e tutor, os professores atuaram em sua maioria nas três atribuições. Evidenciam os desafios no desempenho dos diferentes papéis nesta modalidade de ensino e sugerem indicadores na melhoria dos processos formativos e de atuação. Dentre eles, o exercício da autoria de material didático, o domínio dos diversos recursos de comunicação e interação, a adequação das aulas por meio de web-conferência, entre outros. As funções da docência na EaD articuladas ao conjunto de atividades desenvolvidas com outros profissionais na organização da gestão pedagógica, contribuiu de forma significativa na melhoria do processo pedagógico na produção do material didático e nas atividades de aula, conforme citaram os docentes investigados. Entretanto, avaliaram como positiva a experenciação da docência na EaD. Além disso, evidenciam a influência positiva exercida na significativa mudança nas práticas pedagógicas na educação presencial.

\section{REFERÊNCIAS}

BEZERRA, M.A.; CARVALHO, A.B.G. Tutoria: concepções e práticas na educação a distância. p.232-257. In: SOUSA, R.P., et al. (orgs). Tecnologias digitais na educação [online]. Campina Grande: EDUEPB, 2011. 276 p. Disponível em: < http://books.scielo.org/id/6pdyn/10 >. Acesso: 01 Nov 2017.

CORTELAZZO, lolanda Bueno de Camargo. Práticas Pedagógicas, Aprendizagem e Avaliação em Educação a Distância. Vol. I. Curitiba: InterSaberes, 2013.

CHAQUIME, L.P.; MILL, D. A prática pedagógica na educação a distância e as transformações na docência. SIED-EnPED. São Carlos: UFSCar. 2012. Disponível em:< http://sistemas3.sead.ufscar.br/ojs/index.php/sied/article/view/157>. Acesso em 14 Dez 2017.

HACK, J.R. Introdução à educação a distância. Florianópolis: LLV/CCE/UFSC, 2011. Disponível em: < https://goo.gl/iAqiiK >. Acesso em: 10 Maio 2017

LITWIN, E. (org). Educação a Distância: temas para debate de uma nova agenda educativa. Porto Alegre: Artmed, 2001.

MATTAR, J. Tutoria e Interação em EaD. SP:Cengage Learning, 2012.

MILL, D. R. S.; et.al. Polidocência na educação a distância: múltiplos enfoques. São Carlos: EDUFSCar, 2010. $200 p$ 
OLIVEIRA, C.M.B. Trabalho Docente na Educação a Distância: saberes e práticas. Teresina: EDUFPI, 2013. 108 p.

SCHMID, A. M. Tutorías: los rostros de la educacíon a distancia. Revista da FAEEBA Educação e Contemporaneidade, v.13, n. 22, p. 275-285, 2004.

SCHNEIDER, D.; ARAUJO, K. K.; BEHAR, P. A. Competências dos atores da educação a distância. In: BEHAR, P.A.(Org.) Competências em Educação a Distância. PA:Penso, 2013.

SCHÖN, Donald A. Formar professores como profissionais reflexivos. In: Nóvoa, A. (coord.) Os professores e a sua formação. Lisboa: Dom Quixote, 1995 (p. 207-236).

TARDIF, Maurice. Saberes Decentes e Formação Profissional. 9ª ed. Petrópolis, RJ: Vozes, 2008

UNESC/PPC. Universidade do Extremo Sul Catarinense. Projeto Pedagógico do Curso de Tecnologia em Gestão Comercial a Distância. Criciúma: UNESC, 2015.

ZANETTE, E.N.; et.al. Educação a Distância no Ensino Superior. In: ZANETTE, E.N.; et.al (Orgs). Tecnologias e Inovações nas Práticas Pedagógicas. Jundiaí/SP: Paco Editorial, 2012. p.13-24. 